\title{
Performance and Exit Flow Characteristics of Mixed-Flow Turbines
}

\author{
C. ARCOUMANIS, R.F. MARTINEZ-BOTAS*, J.M. NOURI and C.C. SU
}

Mechanical Engineering Department, Imperial College of Science, Technology and Medicine, London

(Received 22 January 1997; In final form 6 March 1997)

\begin{abstract}
The performance and exit flow characteristics of two mixed-flow turbines have been investigated under steady-state conditions. The two rotors differ mainly in their inlet angle geometry, one has a nominal constant incidence (rotor B) and the other has a constant blade angle (rotor $\mathrm{C}$ ), but also in the number of blades. The results showed that the overall peak efficiency of rotor $C$ is higher than that of rotor $B$. Two different volutes were also used for the tests, differing in their cross-sectional area, which confirm that the new larger area volute turbine has a higher efficiency than the old one, particularly at lower speeds, and a fairly uniform variation with velocity ratio.

The flow exiting the blades has been quantified by laser Doppler velocimetry. A difference in the exit flow velocity for rotors $B$ and $C$ with the new volute was observed which is expected given their variation in geometry and performance. The tangential velocities near the shroud resemble a forced vortex flow structure, while a uniform tangential velocity component was measured near the hub. The exit flow angles for both rotor cases decreased rapidly from the shroud to a minimum value in the annular core region before increasing gradually towards the hub. In addition, the exit flow angles with both rotors were reduced with increasing rotational speeds. The magnitude of the absolute flow angle was reduced in the case of rotor $C$, which may explain the improved steady state performance with this rotor. The results also revealed a correlation between the exit flow angle and the performance of the turbines; a reduction in flow angle resulted in an increase in the overall turbine efficiency.
\end{abstract}

Keywords: Turbochargers, mixed flow turbines, pulsating flows, laser velocimetry, unsteady aerodynamics

\section{INTRODUCTION}

Mixed-flow turbines for automotive turbochargers have been recently investigated both experimen- tally and theoretically. Steady flow results have indicated improved efficiencies when compared to radial-inflow turbines (Naguib [1986]; Chou and Gibbs [1989]; Rodgers [1990]; Ikeya et al. [1992];

* Corresponding author. 
Tsujita et al. [1993]; Minegishi et al. [1995]). Other investigators have not observed a substantial gain in peak efficiency but have suggested advantages in using mixed-flow rotors under pulsating flow conditions (Abidat et al. [1992]). Arcoumanis et al. [1995] have carried out experimental tests under engine representative pulsating conditions, and concluded that higher cycle-averaged efficiencies can be obtained with a mixed-flow rotor geometry.

A mixed-flow turbine overcomes one of the principal limitations of radial-inflow turbines, where stress and material considerations dictate that the blade angle must be zero to maintain radial blade sections and hence keep the centrifugal load in the blades purely tensile (see Fig. 1). It permits the use of non-zero blade angles without departure from the requirement of radial blade fibres, thus introducing an extra degree of freedom in the rotor design. A mixed-flow rotor is capable of achieving a peak efficiency at lower velocity ratios (or higher pressure ratios) when compared with its radial counterpart. This provides a better utilisation of the engine exhaust gas energy since the maximum energy in the exhaust gases is available at high exhaust manifold pressure (Watson and Janota [1982]) which, therefore, improves the engineturbocharger matching. In order to optimise the design of mixed-flow rotors and hence increase its potential in practical applications, a better understanding of the flow processes at the inlet, exit and blade passages of the rotor is necessary. The present experimental study focuses on two mixed-

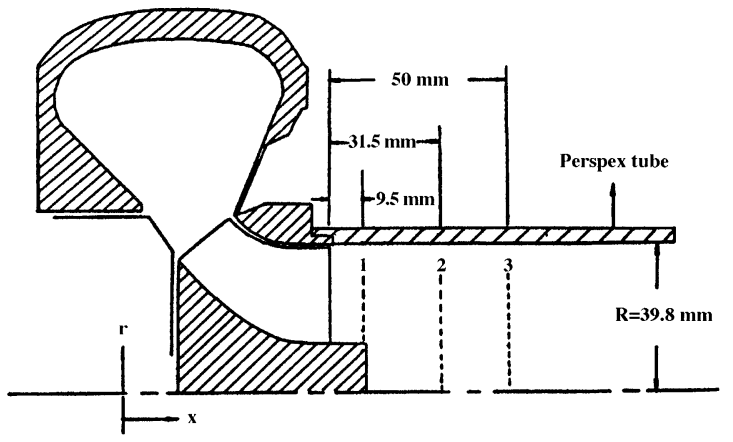

FIGURE 1 Laser measurement locations at the exit of the mixed-flow rotor.
TABLE I The geometry of mixed-flow rotor B

\begin{tabular}{lc}
\hline Rotor tip mean diameter & $83.58 \mathrm{~mm}$ \\
Rotor inlet blade height & $17.99 \mathrm{~mm}$ \\
Rotor length & $32.50 \mathrm{~mm}$ \\
Exducer tip diameter & $78.65 \mathrm{~mm}$ \\
Exducer hub diameter & $27.07 \mathrm{~mm}$ \\
Blade exit angle & $-52^{\circ}$ \\
Number of blades & 12 \\
\hline
\end{tabular}

flow rotor geometries: one with a nominal constant incidence angle (rotor B) and the other with a constant blade angle (rotor C). Rotor B has two more blades and is $7.5 \mathrm{~mm}$ shorter than rotor $\mathrm{C}$. Table I gives the detailed geometry of rotor $\mathbf{B}$.

Due to the nature of the flow through small turbomachines, which is complex with high velocities and time-dependent, the measuring instruments must be robust to withstand the unsteady aerodynamic forces, must have high spatial and temporal resolution and must not disturb the flow. Only optical methods, in particular laser velocimetry, can fulfill these requirements. For such applications, laser-Doppler (LDV) and transit two-focus (L2F) velocimeters have been used widely (e.g., Elder et al. [1986]; Zaidi and Elder [1993]). The preference for one of these two methods depends on many factors, for example, on the number of the available windows, the direction at which the scattered light is collected, the level of flow turbulence and the level of data rate (Elder et al. [1986]; Schodl [1986]). Consideration of all these requirements in the present set up has led to the choice of a laser-Doppler velocimeter for the flow measurements in this research programme. On the other hand, the L2F method has been used to obtain useful velocity and flow angle results in radial turbines at realistic speeds such as by Kitson et al. [1990], Baines and Yeo [1991], Zaidi and Elder [1993] and Benisek [1994]. Limited velocity results have also been obtained using LDV, for example Elder et al. [1986], Khezzar et al. [1987] and Murugan et al. [1994]. The first two studies made measurements in high speed compressors while the last one obtained detailed three-component velocity measurements in the exit of a radial 
turbine but at the well off design speed of 1000 $\mathrm{rpm}$. The last two studies employed a counter for signal processing while Elder et al. used a correlator to eliminate noise from the signals.

The aim of the present work was to study the exit flow of two mixed-flow turbines using a laserDoppler velocimetry system. The performance of the two turbines was also examined in order to be able to relate the variation of the overall efficiency of these rotors to the corresponding exit flows and in particular the flow angles.

\section{FLOW CONFIGURATION AND INSTRUMENTATION}

The present test rig is the same as that used by Hakeem [1995] and a schematic diagram is shown in Fig. 2. Air is supplied to the turbine from two Howden compressors which can provide compressed air of up to 5 bars pressure equivalent to $1 \mathrm{~kg} / \mathrm{s}$ flowrate. The air is filtered through a threestage cyclone and paper filter system. Downstream of the filter system, there are two motorised valves operated from the control panel, one is the main valve for regulating the mass flow rate of air into the turbine rotor and the other acts as a safety valve. When the main valve is turned on, the air enters into a $104.4 \mathrm{~mm}$ diameter pipe. The pipe incorporates a $59.8 \mathrm{~mm}$ diameter orifice plate to measure the mass flow rate of air according to the BS1042 [1981] with an accuracy better than 1.5\%. The air is then heated up to the equivalent turbine inlet design temperature $(333-343 \mathrm{~K})$ by three electrical heaters, two of $36 \mathrm{~kW}$ and one of $9 \mathrm{~kW}$ rating to avoid any condensation of water vapour occurring during the expansion process in the turbine rotor. The air then passes through an instrumented section which contains the necessary static pressure tappings and thermocouples to characterise the turbine inlet flow parameters. This section is connected to the turbine volute through a divergent duct section. After the air enters the turbine volute, it flows through the mixed-flow turbine rotor, before it is discharged into the atmosphere. In order to perform LDV measurements

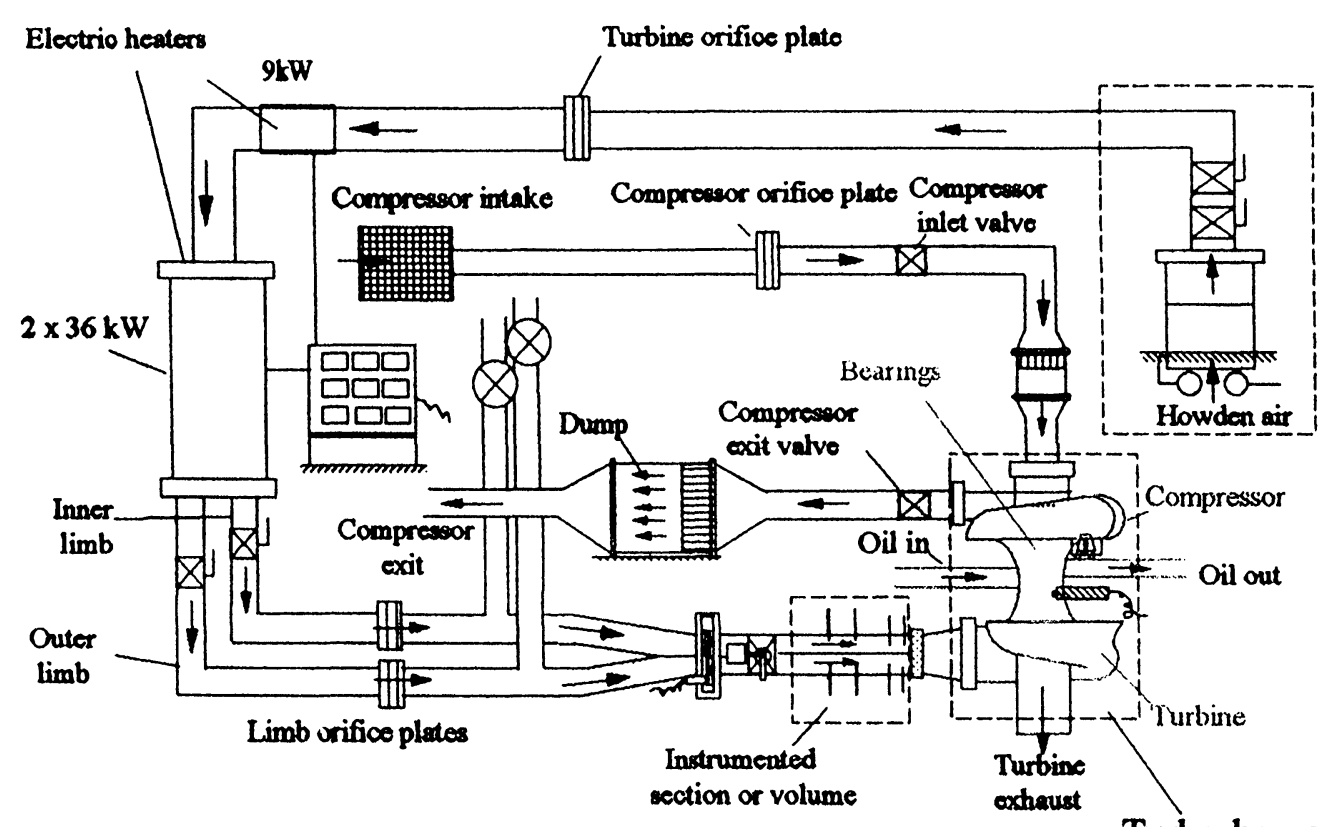

Turbocharger

FIGURE 2 Overall illustration of the turbocharger test rig. 
at the rotor exit plane, the exhaust pipe was replaced with an identical perspex tube $150 \mathrm{~mm}$ long, as shown in Fig. 1. The other end of the perspex tube was connected to the flexible pipe of the exhaust system.

On the compressor side, atmospheric air is sucked into a $96.19 \mathrm{~mm}$ diameter pipe, it then passes through a $59.84 \mathrm{~mm}$ diameter orifice plate, through a throttle valve which is electrically controlled and through a flow straightener that consists of fine gauze filters and honeycombs to generate a uniform flow prior to entering the inlet of the compressor with a $127 \mathrm{~mm}$ impeller diameter. A manual throttle valve, which is controlled by a Bowden cable from the control panel, is located downstream of the compressor exit. The compressor exhaust gas is then dumped into a large plenum which contains a honeycomb flow straightener, to recover the kinetic energy of the flow and hence to achieve a more accurate measurement of the total temperature at the compressor's exit. The exhaust gas eventually discharges into the same exhaust system through a flexible hose.

The turbocharger test rig facility is capable of testing single-entry or twin-entry radial-inflow or mixed-flow turbines under steady-state or pulsating flow conditions. A detailed description of the test rig is given by Hakeem and Khezzar [1994].

The steady-state performance characteristics (total-to-static efficiency and swallowing capacity) were evaluated by means of the energy balance method, where the turbine actual output power is estimated by measuring the power absorbed by the loading device (centrifugal compressor) and the heat discharged to the bearing lubricating oil. For this purpose, a good number of pressures and temperatures need to be measured. The measuring positions for these physical quantities were described by Hakeem and Khezzar [1994]. Two pressure transducers installed in a 24-channel Scanivalve are used to measure the wall static pressure during the tests. One of the pressure transducers (type Druck PDCR 23D, range: \pm 3.5 bar (gauge)) is used for the high pressure measurement, and the other (type Druck PDCR 22, range: \pm 0.35 bar (gauge)) for the low pressure measurement. Two shielded type-E thermocouples are used to measure the turbine inlet temperature. All instruments were calibrated prior to the performance tests resulting in uncertainties of $8.46 \times 10^{-3}$ bar for the high pressure transducer, $0.897 \times 10^{-3}$ bar for the low pressure transducer, and $0.6 \mathrm{~K}$ for the thermocouples.

The laser Doppler velocimeter was operated in the dual-beam near-forward scattering mode and comprised an argon-ion laser (Spectra Physics) operating in the green light with a wavelength of $0.514 \mu \mathrm{m}$ and power of up to $1 \mathrm{~W}$, a diffractiongrating arrangement to divide the laser beam into two of equal intensity and to provide frequency shifts up to $14 \mathrm{MHz}$, a collimating and a focusing lens for bringing the two beams to an intersection volume, a photomultiplier, and a frequency counter (TSI model 1990) interfaced to a microcomputer; the system is similar to that described by Arcoumanis et al. [1996]. The intersection volume was approximately $495 \mu \mathrm{m}$ in length and $42 \mu \mathrm{m}$ in diameter, with a fringe spacing of $3.04 \mu \mathrm{m}$. The signals from the photomultiplier were processed by the TSI counter which was operated in the "single measurement per burst" (SMB) mode with simultaneous frequency validation. The digital output of the counter was fed into a microcomputer, via a purpose-built DOSTEK DMA interface card, where the ensemble averaged values of the mean and $\mathrm{rms}$ velocities were estimated from between 2000 to 3000 sample points over many turbine rotations.

It should be noted that these averaged values obtained over $360^{\circ}$ of turbine rotation represent a true circumferential average. In order to resolve the details of the flow, it will be necessary to average over a much smaller angle, say for example $1^{\circ}$, of the turbine rotation. The values averaged over many turbine rotations may contain blade-to-blade mean flow variations, hence the ensemble-averaged rms velocity values obtained in this way may overestimate the true turbulence. The use of circumferential averages was found to be sufficient for the purpose of assessing the suitability of the 
present optical measuring/processing system and providing means for comparison of the exit flow between the two rotors, which may help to explain the differences observed in their steady-state performance. However, the development of an averaging technique over very small angles is in progress with the aim of achieving a spatial resolution of up to $1 \mu \mathrm{s}$, equivalent to $0.36^{\circ}$ of the turbine rotation at a turbine speed of $60000 \mathrm{rpm}$.

Exit flow measurements were obtained at a nearforward scattering angle at three exit planes: $50^{\circ}$ to the optical axis for the first exit plane (where the presence of the hub limited any shallower angle, see Fig. 1) and $30^{\circ}$ for the other two downstream planes. The signal to noise ratio was initially very good, but subsequent window fouling due to the seeded oil and dust particles caused rapid deterioration in its quality. This was a frequent problem especially for the measurements at the higher design speeds which became increasingly more tedious and time consuming.

A source of measurement uncertainty can be the size of the silicone oil droplets and their ability to follow the flow fluctuations. The droplets were generated by an air-blast atomiser and added to the flow in the divergent duct upstream of the volute. The atomiser has been shown to produce droplets with Sauter mean diameter, $d_{p}$, of up to $2 \mu \mathrm{m}$ which corresponds to a maximum effective Stokes number of 0.1 , defined as the ratio of the particle response time $\left(\tau_{p}=\rho_{p} d_{p}^{2} / 18 \mu\right)$ to the flow response time $\left(\tau_{f}=L / U_{t}\right)$ where $\rho_{p}, \mu, L$ and $U_{t}$ are the particle density, the fluid dynamic viscosity, the length of the blade span at exit and the rotor tip velocity, respectively. This implies that the droplets on average follow the mean flow although occasional larger droplets may occur, giving rise to an uncertainty due to their size which can be considered to be negligible. Uncertainties due to velocity gradients were minimised by using a small measuring volume and collecting the light off the optical axis. The statistical uncertainty was estimated to be less than $1.5 \%$ and $3.2 \%$ in the mean and $\mathrm{rms}$ value of the velocity respectively, with a $95 \%$ confidence level and a turbulence intensity of
$30 \%$. The maximum counting ambiguity of the TSI counter having a clock frequency of $1000 \mathrm{MHz}$ was $1.1 \%$ of the Doppler frequency shift. The whole optical system was mounted on a 3-dimensional traversing mechanism with a positional uncertainty of $0.025 \mathrm{~mm}$.

\section{RESULTS AND DISCUSSION}

\section{Performance Measurements}

The steady-state performance of turbines B and C was investigated by Hakeem [1995] and Chen et al. [1992] in a volute made out of epoxy, a material not suitable to install optical windows. It was therefore found necessary to produce a more durable volute, and a cast iron one was manufactured by Holset Engineering. As shown in Fig. 3 the housing geometry of the new volute is different from the old one which was designed following one-dimensional analysis and assuming the flow satisfies the free vortex law upstream of the rotor; the casing configuration analysis was done without considering friction and other losses (Abidat [1991]). The new volute is based on a twin-entry turbine whose partition wall was removed to obtain the desired single entry geometry. It is therefore expected that a larger swallowing capacity can be achieved. Before carrying out the LDV measurements, it was necessary to do steady-state performance tests in order to determine the conditions of peak efficiency to be used for the LDV measurements.

The total-to-static efficiency was calculated using the energy balance method mentioned in the preceding section and can be defined as

$$
\begin{aligned}
\left(\eta_{t-s}\right)_{\text {Steady }} & =\frac{\left(\dot{W}_{T}\right)_{\text {Actual }}}{\left(\dot{W}_{T}\right)_{\text {Isentropic }}} \\
& =\frac{\left(\dot{W}_{C}\right)_{\text {Actual }}+\left(\dot{Q}_{O}\right)_{\text {Actual }}}{\left(\dot{W}_{T}\right)_{\text {Isentropic }}},
\end{aligned}
$$

which can be rewritten in the following form by introducing the specific heat capacity at constant 


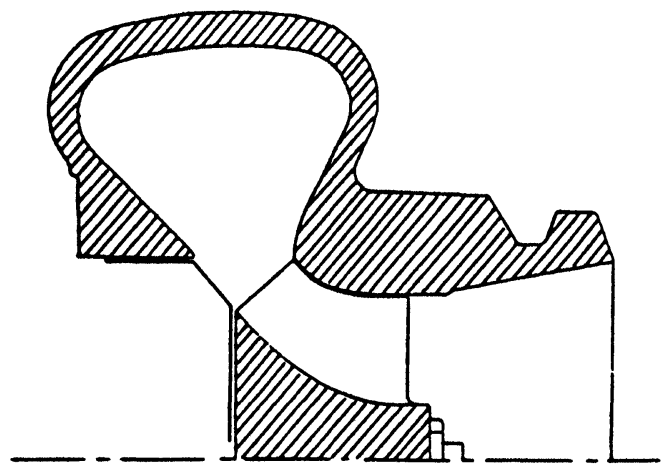

(a)

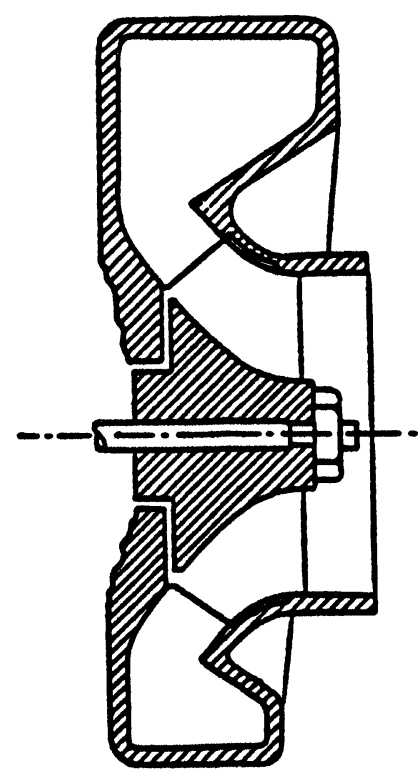

(b)

FIGURE 3 Housing geometry of mixed-flow turbine volute (a) new design; (b) old design.

pressure, i.e.

$$
\begin{aligned}
\left(\eta_{t-s}\right)_{\text {Steady }}= & \left\{\dot{m}_{c}\left[\int_{\text {in }}^{\text {out }} c_{p, c} \mathrm{~d} T+\frac{1}{2}\left(U_{\text {out }}^{2}-U_{\text {in }}^{2}\right)_{c}\right]\right. \\
& \left.+\dot{m}_{\text {oil }} \int_{\text {in }}^{\text {out }} c_{p, \text { oil }} \mathrm{d} T\right\} / \dot{m}_{T}\left[\int_{3}^{1} c_{p, c} \mathrm{~d} T+\frac{1}{2} U_{1}^{2}\right] .
\end{aligned}
$$

This parameter is usually plotted against velocity ratio given by

$$
\frac{U_{2}}{C_{i s}}=\frac{\pi d_{2} N}{60\left(\sqrt{2\left[\int_{3}^{1} c_{p} \mathrm{~d} T+\frac{1}{2} u_{1}^{2}\right]}\right)},
$$

where the isentropic expansion velocity, $C_{i s}$, is a function of the total-to-static pressure ratio and represents the velocity that would be obtained if the working fluid was expanded in an ideal nozzle over the same pressure ratio as that of the turbine.

A pseudo-non-dimensional mass flow parameter (M.P.) is used to evaluate the swallowing capacity of the turbine, it is defined as

$$
\text { M.P. }=\frac{\dot{m}_{T} \sqrt{T_{01}}}{P_{01}},
$$

which is plotted against the pressure ratio (P.R.) given by

$$
\text { P.R. }=\frac{P_{01}}{P_{e}},
$$

where $P_{e}$ is the turbine exit pressure (atmospheric in this case).

The performance tests were carried out at five different rotational speeds covering a range of $50 \%$ to $90 \%$ equivalent design speeds. The total-tostatic efficiency characteristics of the mixed-flow turbine rotor $\mathrm{B}$ with the new and old volute are shown in Fig. 4. It is clear that the new volute gives rise to higher overall efficiency levels, particularly at low rotational speeds and high velocity ratios. Table II summarizes the difference in performance between the two volutes; the peak efficiency levels for the new volute were several percentage points higher, ranging from 4 points at $50 \%$ to 0.8 points at $90 \%$ equivalent design speed. The results with the new volute also show that the efficiency increases with rotational speed up to the $70 \%$ equivalent design speed, after which the efficiency remains nearly the same except at high velocity ratios. The new volute efficiency curves become fairly flat at speeds between $70 \%$ and $90 \%$. 

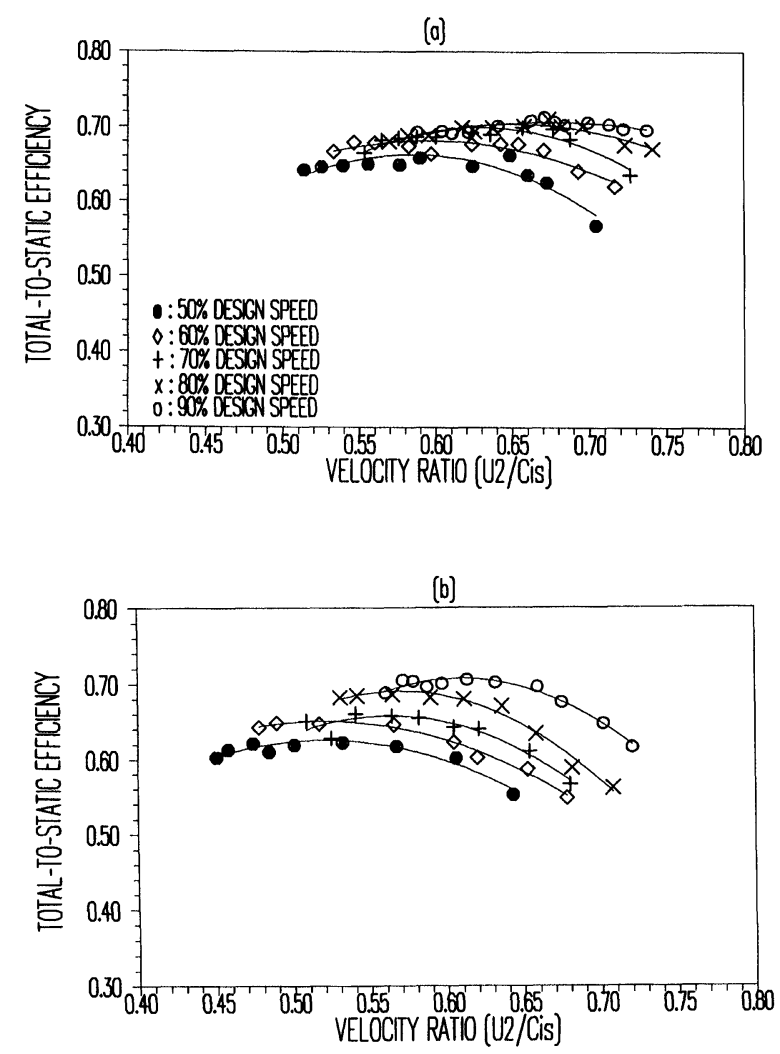

FIGURE 4 Efficiency characteristics of mixed-flow turbine rotor B (a) new volute; (b) old volute (Hakeem, 1995).
It is clear that a reduced sensitivity to the rotational speed has been achieved with the new volute, which is in line with typical radial-inflow turbine results (Dale and Watson [1986]). This behaviour will tend to improve the transient performance of the turbine since a change in the rotational speed will produce a small change in efficiency levels. It is also evident that the efficiency curve for a given constant rotational speed is flatter with the new volute. This result points towards an improved pulsating behaviour of the turbine; during a typical engine pulse the turbine operating point moves from high to low velocity ratios or vice versa at fairly constant rotational speeds (Hakeem [1995]).

For turbine rotor $\mathrm{C}$, the test results are shown in Fig. 5 and Table III. It can be seen that the new volute has similar effects on turbine efficiency. The results also show that, as with rotor $\mathrm{B}$, the efficiency curves do not vary much after the $70 \%$ equivalent design speed except at high velocity ratios. The peak efficiency of both rotors reaches a maximum at $70 \%$ equivalent design speed, which prompted the decision to perform the LDV measurements at $50 \%$ and $70 \%$ equivalent design speeds using the new volute. It is also clear that the

TABLE II The total-to-static efficiency of turbine rotor B with old and new volute at choke, peak efficiency and surge test conditions

\begin{tabular}{|c|c|c|c|c|}
\hline Test condition & $\begin{array}{c}\text { Equivalent design speed } \\
(\%)\end{array}$ & $\begin{array}{c}\eta_{\mathrm{t}-\mathrm{s}, \mathrm{old}} \\
(\%)\end{array}$ & $\begin{array}{l}\eta_{t-s, \text { new }} \\
(\%)\end{array}$ & $\eta_{t-\mathrm{s}, \text { new }}-\eta_{\mathrm{t}-\mathrm{s}, \text { old }}$ \\
\hline $\begin{array}{l}\text { compressor } \\
\text { choke }\end{array}$ & $\begin{array}{l}50 \\
60 \\
70 \\
80 \\
90\end{array}$ & $\begin{array}{l}60.3 \\
64.3 \\
65.2 \\
68.3 \\
68.9\end{array}$ & $\begin{array}{l}64.2 \\
66.7 \\
66.6 \\
68.1 \\
69.4\end{array}$ & $\begin{array}{r}3.9 \\
2.4 \\
1.4 \\
-0.2 \\
0.5\end{array}$ \\
\hline $\begin{array}{l}\text { turbine } \\
\text { peak efficiency }\end{array}$ & $\begin{array}{l}50 \\
60 \\
70 \\
80 \\
90\end{array}$ & $\begin{array}{l}62.3 \\
64.9 \\
66.1 \\
68.6 \\
70.6\end{array}$ & $\begin{array}{l}66.3 \\
68.0 \\
70.0 \\
71.1 \\
71.4\end{array}$ & $\begin{array}{l}4.0 \\
3.1 \\
3.9 \\
2.5 \\
0.8\end{array}$ \\
\hline $\begin{array}{l}\text { compressor } \\
\text { surge }\end{array}$ & $\begin{array}{l}50 \\
60 \\
70 \\
80 \\
90\end{array}$ & $\begin{array}{l}55.3 \\
54.9 \\
56.7 \\
56.2 \\
61.6\end{array}$ & $\begin{array}{l}56.8 \\
62.1 \\
63.6 \\
67.2 \\
69.7\end{array}$ & $\begin{array}{r}1.5 \\
2.2 \\
6.9 \\
11.0 \\
8.1\end{array}$ \\
\hline
\end{tabular}




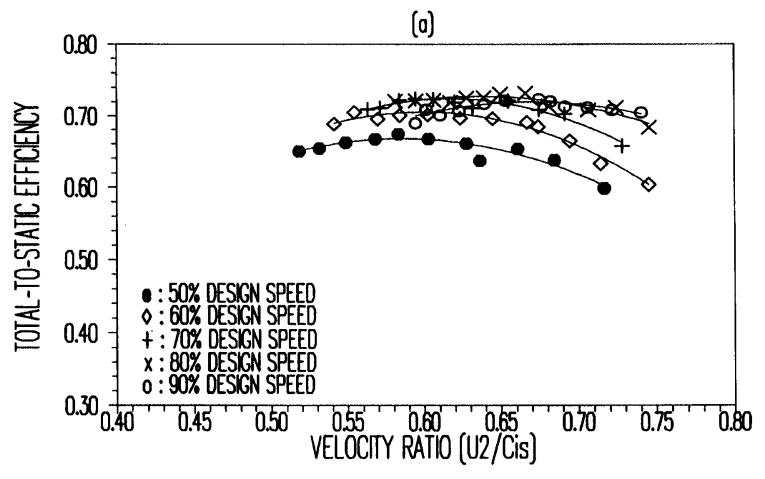

(b)

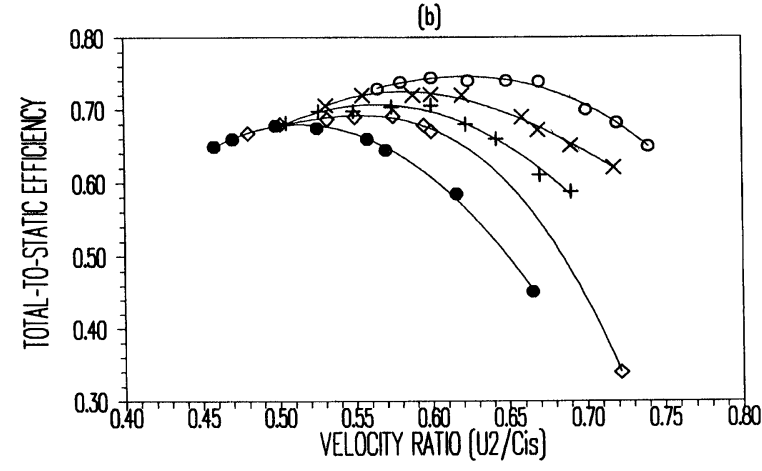

FIGURE 5 Efficiency characteristics of mixed-flow turbine rotor C (a) new volute; (b) old volute (Chen et al., 1992). efficiency of rotor $\mathrm{C}$ is higher than rotor $\mathrm{B}$ at all design speeds so that the overall peak efficiency of rotor $\mathrm{C}$ is typically 2 percentage points higher.

The swallowing capacity of rotor B with the new and old volute is shown in Fig. 6; the swallowing capacity has increased significantly with the new volute, for example at $90 \%$ equivalent design speed and for the same pressure ratio of 1.875 , the mass flow parameterincreases by $35 \%$ with thenew volute. This is mainly because of the increased flow area in the passage of the new volute. On the other hand, Fig. 7 shows that the swallowing capacity of rotor $C$ with the new volute is similar to that of rotor B.

From the preceding paragraphs, it is evident that the new volute has enhanced the turbine overall performance, mainly due to the geometric differences between the two volutes, as shown in Fig. 3. The shroud line of the old volute protrudes well into the flow passage of the volute and forms a very sharp corner near the volute exit, which might obstruct the flow into the rotor; in addition the turning curvature of the top wall of the volute is large. Martinez-Botas et al. [1996] in their numerical investigation have pointed out that these features create disturbed flow conditions near the sharp corner of the volute, where the total pressure loss was shown to increase and the overall

TABLE III The total-to-static efficiency of turbine rotor $\mathrm{C}$ with old and new volute at choke, peak efficiency and surge test conditions

\begin{tabular}{lcccc}
\hline Test condition & $\begin{array}{c}\text { Equivalent design speed } \\
(\%)\end{array}$ & $\begin{array}{c}\eta_{\mathrm{t}-\mathrm{s} \text { old }} \\
(\%)\end{array}$ & $\begin{array}{c}\eta_{\mathrm{t}-\mathrm{s} \text {,new }} \\
(\%)\end{array}$ & $\eta_{\mathrm{t}-\mathrm{s}, \text { new }}-\eta_{\mathrm{t}-\mathrm{s} \text {,old }}$ \\
\hline compressor & 50 & 65.0 & 65.0 & 0.0 \\
choke & 60 & 66.8 & 68.9 & 2.1 \\
& 70 & 68.2 & 71.0 & 2.8 \\
& 80 & 70.6 & 72.2 & 1.6 \\
turbine & 90 & 72.9 & 69.0 & -3.9 \\
peak efficiency & 50 & 67.8 & 67.5 & -0.3 \\
& 60 & 69.1 & 70.6 & 1.5 \\
& 70 & 70.6 & 72.5 & 1.9 \\
compressor & 80 & 72.1 & 73.3 & 1.2 \\
surge & 90 & 74.4 & 72.4 & -2.0 \\
& 50 & 45.2 & 59.9 & 14.7 \\
& 60 & 34.0 & 60.5 & 26.5 \\
& 70 & 58.8 & 65.8 & 7.0 \\
\hline
\end{tabular}




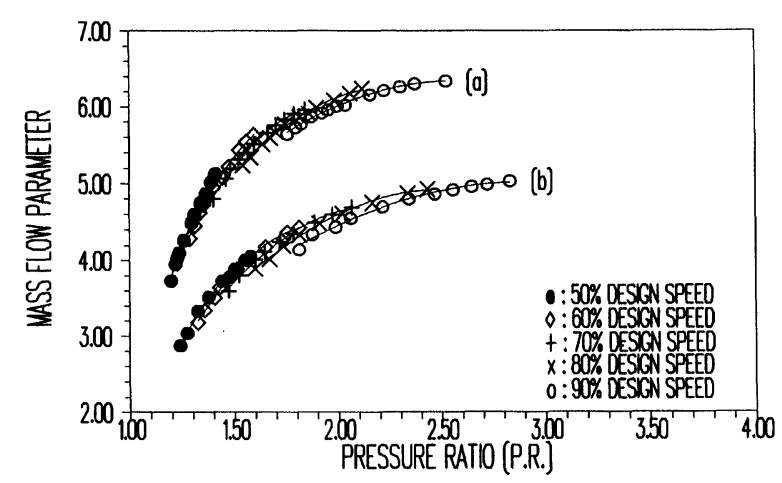

FIGURE 6 Mass flow rate characteristics of mixed-flow turbine rotor B (a) new volute; (b) old volute (Hakeem, 1995)

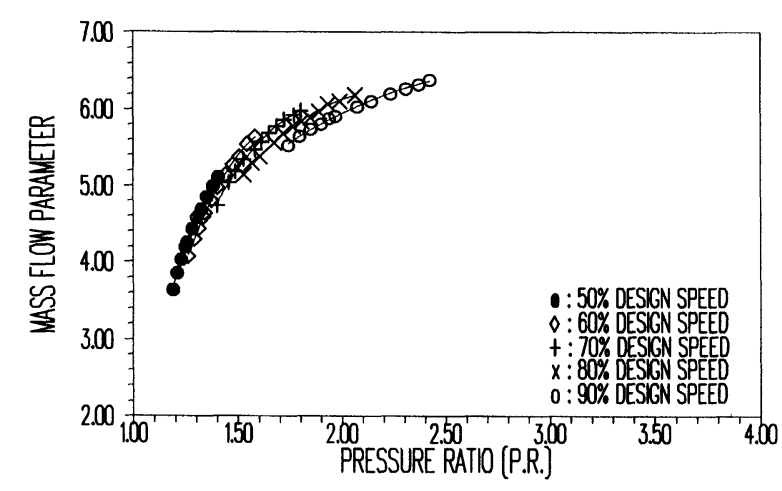

FIGURE 7 Mass flow rate characteristics of mixed-flow turbine rotor $\mathrm{C}$ with new volute.

performance of the volute was thus reduced. They also suggested that reducing the sharpness and curvature, that is adopting a smoother inlet profile, will improve the flow situation. The new volute has a smoother curved wall without significant discontinuities, which allows the flow to be better guided than the old one.

\section{Velocity Measurements}

Measurements of the axial and tangential mean and rms velocity components at the exit of rotors B and $\mathrm{C}$ were obtained at the peak efficiency condition at $50 \%$ and $70 \%$ equivalent design speeds corresponding to 29500 and $41500 \mathrm{rpm}$, respectively (see Table IV). Measurements were taken at three different axial planes: $\mathrm{X}=9.5 \mathrm{~mm}$,
$31.5 \mathrm{~mm}$ and $50.0 \mathrm{~mm}$ from the trailing edge of the blades as shown in Fig. 1. The radial distance is normalised with the exit pipe inner radius, $\mathrm{R}$. It should be emphasised that the results presented here are ensemble-averaged over many turbine rotations and are therefore circumferentially averaged quantities.

Figure 8 presents the axial mean and rms velocities of both rotors at three axial locations
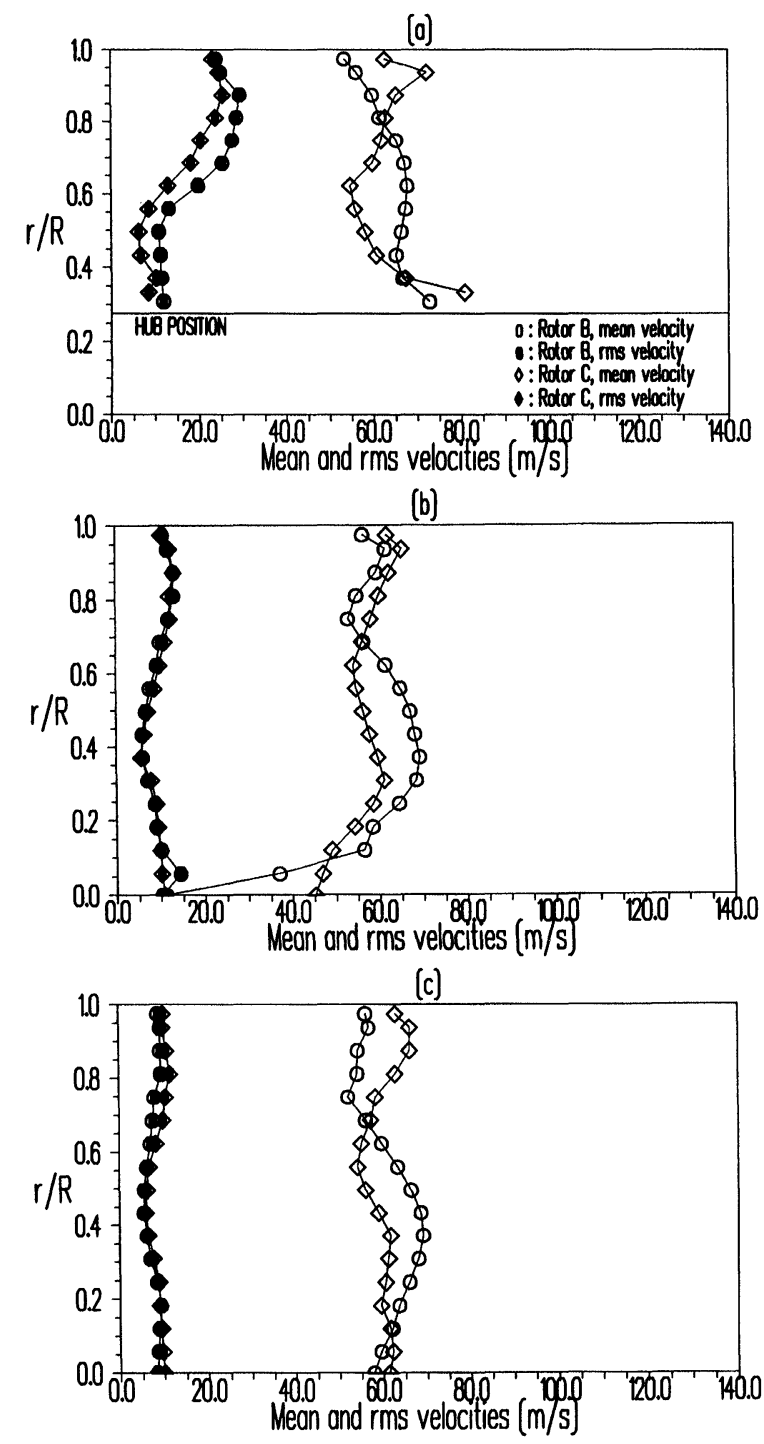

FIGURE 8 Exit axial mean and rms velocity of mixed-flow rotors $\mathrm{B}$ and $\mathrm{C}$ for the $50 \%$ equivalent design speed at three axial locations (a) $X=9.5 \mathrm{~mm}$; (b) $X=31.5 \mathrm{~mm}$; (c) $X=50.0 \mathrm{~mm}$. 
TABLE IV Flow conditions at peak efficiency for the LDV measurements

\begin{tabular}{lcccc}
\hline Rotor type & \multicolumn{2}{c}{ B } & C \\
\hline Equivalent design speed (\%) & 50 & 70 & 50 & 70 \\
$\eta_{\mathrm{t} \sim \mathrm{s}}$ & 0.6615 & 0.7007 & 0.6732 & 0.7238 \\
$\mathrm{U}_{2} / \mathrm{C}_{\mathrm{is}}$ & 0.5992 & 0.6060 & 0.5989 & 0.6063 \\
$\mathrm{P}_{\mathrm{ol}} / \mathrm{P}_{\mathrm{e}}$ & 1.2884 & 1.6487 & 1.2853 & 1.6496 \\
$\dot{m}_{T} \sqrt{T_{o 1}} / P_{o 1}$ & 4.5236 & 5.6834 & 4.4676 & 5.6890 \\
$\dot{m}_{\text {orif }}(\mathrm{kg} / \mathrm{sec})$ & 0.3246 & 0.5257 & 0.3231 & 0.5229 \\
$\dot{m}_{\mathrm{LDV}}(\mathrm{kg} / \mathrm{sec})$ & 0.3202 & 0.5113 & 0.3177 & 0.5368 \\
$\left(\left(\dot{m}_{\mathrm{LDV}}-\dot{m}_{\text {orif }}\right) / \dot{m}_{\text {orif }}\right) \times 100(\%)$ & -1.36 & -2.74 & -1.67 & 2.66 \\
\hline
\end{tabular}

for the $50 \%$ equivalent design speed. At the first plane $(X=9.5 \mathrm{~mm})$ close to the trailing edge of the blades, a different mean flow distribution can be seen for the two rotors, with rotor $\mathrm{B}$ being more uniform. The axial velocity for rotor B increases from shroud to hub, and becomes almost constant in the annular core region before increasing towards the hub. Rotor $\mathrm{C}$, on the other hand, exhibits a plug-type profile with a minimum velocity of $55 \mathrm{~m} / \mathrm{s}$ at $\mathrm{r} / \mathrm{R}=0.6$ rising to 72 and $81 \mathrm{~m} / \mathrm{s}$ close to the shroud and hub, respectively. The results indicate that the axial flow development within the blades, from inlet to the exit, of the two rotors is different which is due to the different inlet blade angle, camberline and blade length (Chen et al. [1992]). They also suggest that the radial flow distribution of the two rotors from the shroud to the hub is different. Further downstream at $\mathrm{X}=$ $31.5 \mathrm{~mm}$, (Fig. $8(\mathrm{~b})$ ) the velocity profiles become more uniform and similar in pattern exhibiting two peaks. Close to the axis of rotation in the wake of the hub and shaft assembly, the velocity decreases rapidly as expected. This effect is more pronounced with rotor B since it is shorter in length and the measuring location is closer to the region of the wake. At $\mathrm{X}=50.0 \mathrm{~mm}$ (Fig. 8(c)) the flow is further developed and the differences between the two rotors are reduced; the effect of the wake in the central region diminishes considerably.

The rms velocities of Fig. 8(a) at the exit of the rotors show large variations across the blade span with higher values close to the shroud which are reducing towards the hub; the rms levels for rotor $\mathrm{B}$ are higher everywhere. The contribution of peri- odic components of the mean flow due to the blade passage can be in part responsible for these high levels of the rms velocity, particularly close to the shroud. This was evident from the probability density function, pdf, of the velocity fluctuations which exhibited a bimodal distribution with large velocity variations from one blade to another, i.e. from the suction side to the pressure side. Further downstream, at $X=31.5 \mathrm{~mm}$ and $50.0 \mathrm{~mm}$, the $\mathrm{rms}$ velocity distributions are much more uniform with lower values than those at the exit, indicating the reduction of the periodic influence of the mean flow and the diffusion of turbulence. The rms values with both rotors are very similar with average values of around 10 and $8 \mathrm{~m} / \mathrm{s}$ at $\mathrm{X}=$ $31.5 \mathrm{~mm}$ and $50.0 \mathrm{~mm}$, respectively.

At the higher equivalent design speed of $70 \%$, Fig. 9, a similar flow pattern to those at the lower speed can be seen, giving a maximum velocity of $116 \mathrm{~m} / \mathrm{s}$ for rotor B and $118 \mathrm{~m} / \mathrm{s}$ for rotor $\mathrm{C}$ at the exit plane near the hub position. The periodicity of the flow induced by the blade passages was stronger than at the lower speed and was observed further downstream at $\mathrm{X}=31.5 \mathrm{~mm}$ and even at $\mathrm{X}=50.0 \mathrm{~mm}$ close to the shroud. The flow in the wake of the hub and shaft assembly with rotor $\mathrm{C}$ was somehow unsteady with large variations in their mean velocity causing a skewed pdf and high rms velocities; this effect was stronger in the tangential component of velocity where together with the very high levels of turbulence intensity, swirl flow precession could be present around the center of the exit pipe. Attempts were made to quantify the precessing frequency by fast Fourier 
transform (FFT) but due to the low data rate $(1 \mathrm{kHz})$ this was not possible.

The mass flow rates were calculated by integrating the axial mean velocity profiles of Figs. 8 and 9 and compared to those obtained from the orifice plate. The results are presented in Table IV in a percentage form, with the maximum difference between the two of $2.7 \%$. This level of agreement is
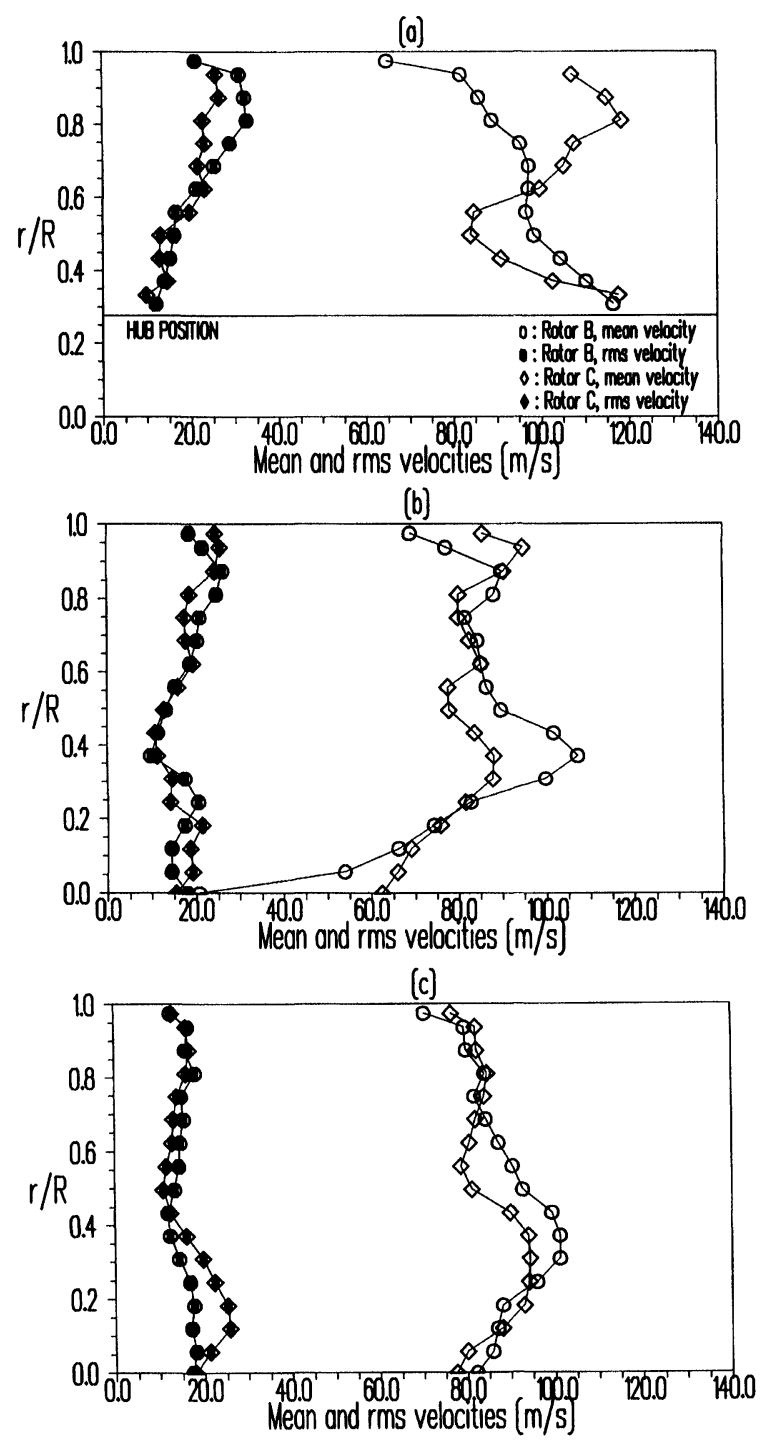

FIGURE 9 Exit axial mean and rms velocity of mixed-flow rotors $\mathrm{B}$ and $\mathrm{C}$ for the $70 \%$ equivalent design speed at three axial locations (a) $X=9.5 \mathrm{~mm}$; (b) $X=31.5 \mathrm{~mm}$; (c) $X=50.0 \mathrm{~mm}$. very satisfactory considering the errors involved in the velocity measurements, in the integration of the velocity profiles and in the calculation of the local air flow density.

The variation of the tangential mean and rms velocities at the lower speed across the blades is presented in Fig. 10. It shows two distinct flow regions at the exit plane of $X=9.5 \mathrm{~mm}$, one close
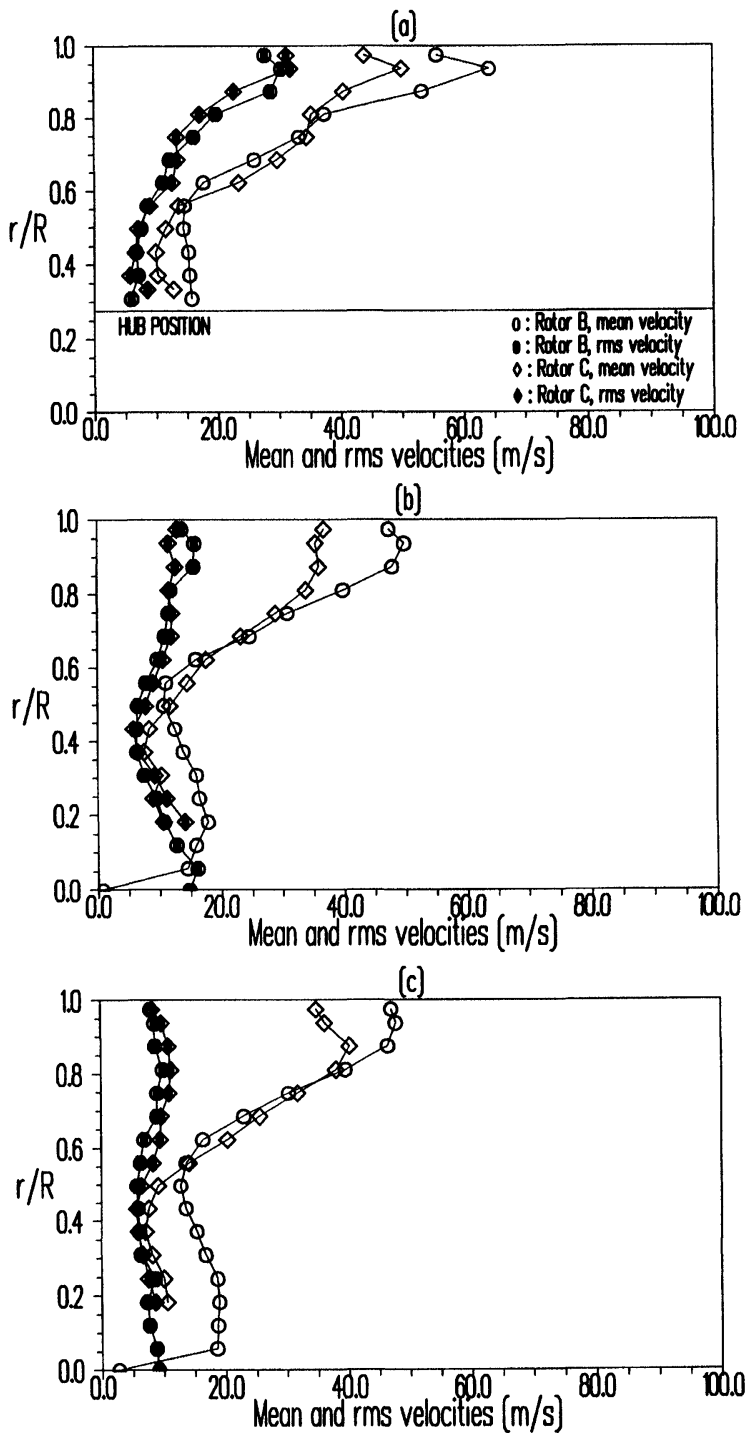

FIGURE 10 Exit tangential mean and rms velocity of mixed-flow rotors $\mathrm{B}$ and $\mathrm{C}$ for the $50 \%$ equivalent design speed at three axial locations (a) $X=9.5 \mathrm{~mm}$; (b) $X=31.5 \mathrm{~mm}$; (c) $\mathrm{X}=50.0 \mathrm{~mm}$. 
to the shroud where the tangential velocity increases rapidly from about $r / R=0.55$ towards the shroud and a second region from this point towards the hub where the tangential velocity becomes uniform with only a gradual increase close to the hub. The flow in the outer region (close to the shroud) in rotor $\mathrm{B}$ tends to behave as a forced vortex (as radius increases, there is an increase in the tangential velocity and a decrease in the axial velocity, assuming negligible radial flow); this effect is not so clear in rotor $\mathrm{C}$. Further downstream at $\mathrm{X}=$ $31.5 \mathrm{~mm}$ and $50.0 \mathrm{~mm}$, the flow patterns change given that there is no longer a hub present. The minimum velocity between the two flow regions is located at almost the same place. The second flow region is extended to cover the central region, with the swirl velocity increasing slowly to a peak close to the centre before dropping again.

At the higher design speed (Fig. 11) similar flow patterns can be seen at all locations except that the position of the minimum velocity is closer to the hub (at around $r / R=0.45$ ), and the swirling flow induced by the action of the blades becomes more dominant as the speed increases. Furthermore, the tangential velocity increases at a faster rate close to the axis.

A clear difference between swirling flows obtained with the two rotors is that the tangential mean velocity is consistently lower for rotor $\mathrm{C}$. At the lower rotor speed and in the first exit plane, the maximum value of the tangential velocity is $64 \mathrm{~m} / \mathrm{s}$ and $50 \mathrm{~m} / \mathrm{s}$ for rotors $\mathrm{B}$ and $\mathrm{C}$, respectively; the tangential velocity close to the hub is of the order of 15 and $10 \mathrm{~m} / \mathrm{s}$ respectively. The corresponding values at the higher design speed are 77 and $52 \mathrm{~m} / \mathrm{s}$ close to the shroud and 19 and $15 \mathrm{~m} / \mathrm{s}$ close to the hub for rotors $\mathrm{B}$ and $\mathrm{C}$, respectively. The reasons for the lower swirl velocities with rotor $\mathrm{C}$ may be attributed to the longer rotor length and the fact that the flow is better guided by the blades. The results also indicate that the exit kinetic energy loss is reduced, which may explain the increase in overall efficiency of this rotor. It is also evident from Figs. 10 and 11, that the tangential mean velocities do not scale with rotor speed; this is also reflected in the overall performance curves which show higher efficiencies at the higher speed.

The variation of the absolute velocity for rotors $\mathrm{B}$ and $\mathrm{C}$ is presented in Figs. 12 and 13 for $50 \%$ and $70 \%$ equivalent design speeds, respectively. The results show similar trends to those of the axial mean velocity distribution, with the differences

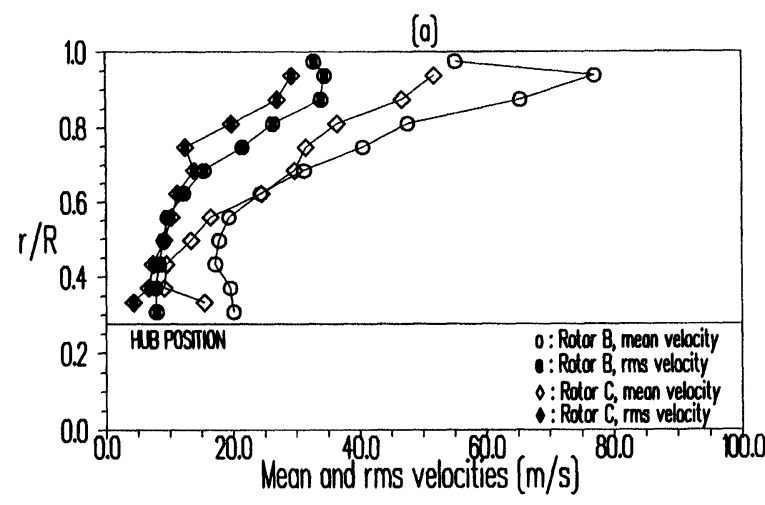

(b)
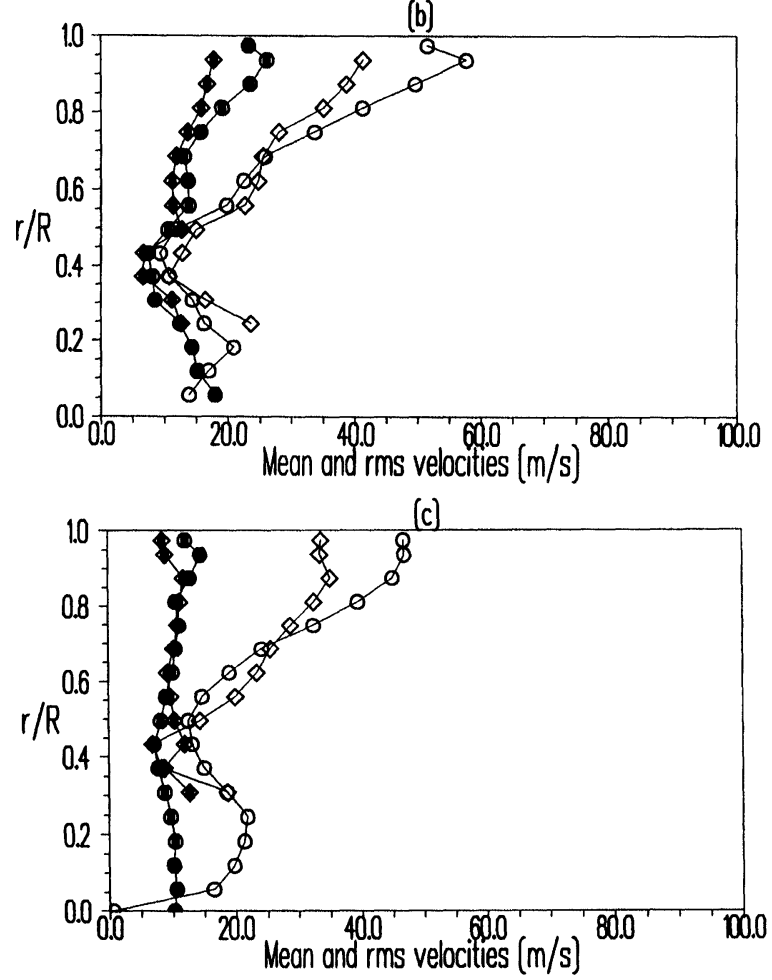

FIGURE 11 Exit tangential mean and rms velocity of mixedflow rotors $\mathrm{B}$ and $\mathrm{C}$ for the $70 \%$ equivalent design speed at three axial locations (a) $\mathrm{X}=9.5 \mathrm{~mm}$; (b) $\mathrm{X}=31.5 \mathrm{~mm}$; (c) $\mathrm{X}=50.0 \mathrm{~mm}$. 


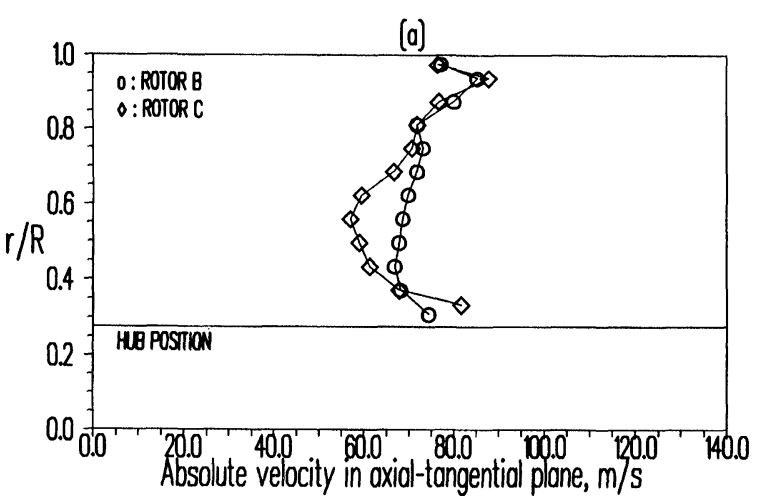

(b)
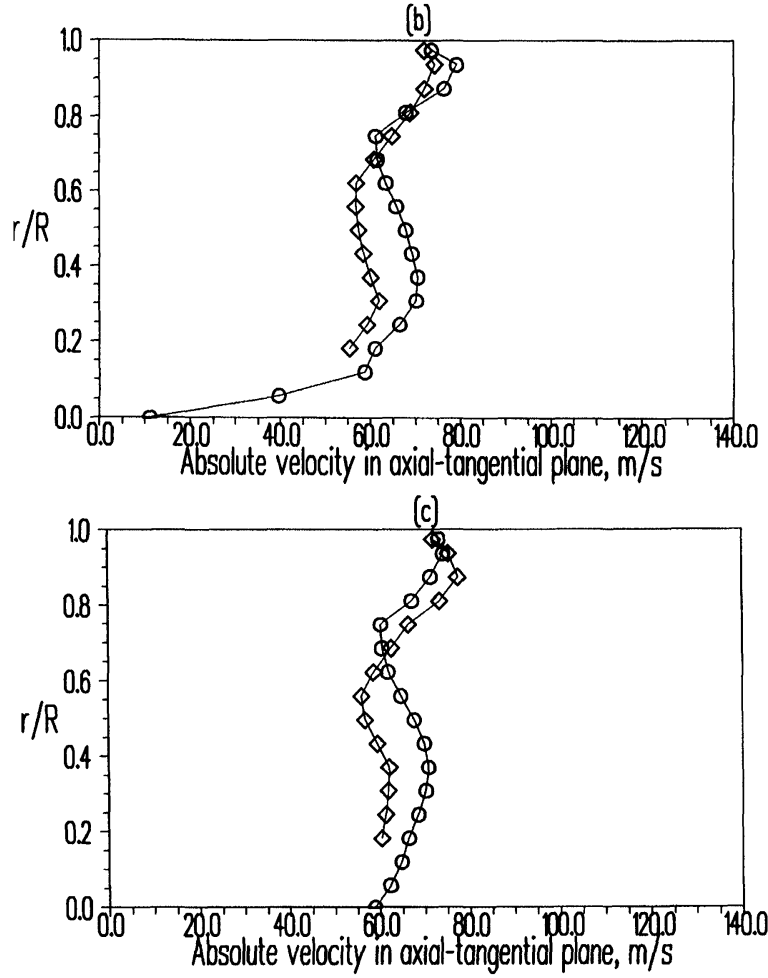

FIGURE 12 Exit absolute velocity of mixed-flow rotors B and $\mathrm{C}$ for the $50 \%$ equivalent design speed at three axial locations (a) $X=9.5 \mathrm{~mm}$; (b) $X=31.5 \mathrm{~mm}$; (c) $X=50.0 \mathrm{~mm}$.

between the two rotors reduced as expected due to the similarity of the tangential velocity components between the two cases.

Figures 14 and 15 represent the variation of the absolute flow angle, $\alpha=\tan ^{-1}(W / U)$, for the $50 \%$ and $70 \%$ equivalent design speeds. The trend seems to follow a similar pattern to the tangential velocity. In general the flow angle decreases from
(0)

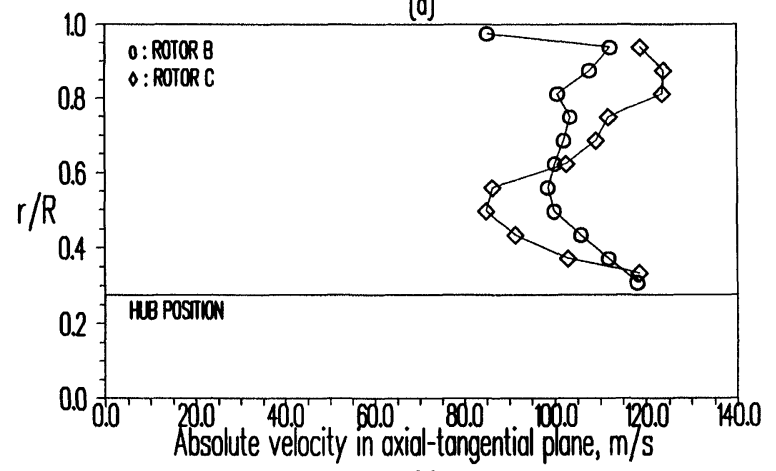

(b)

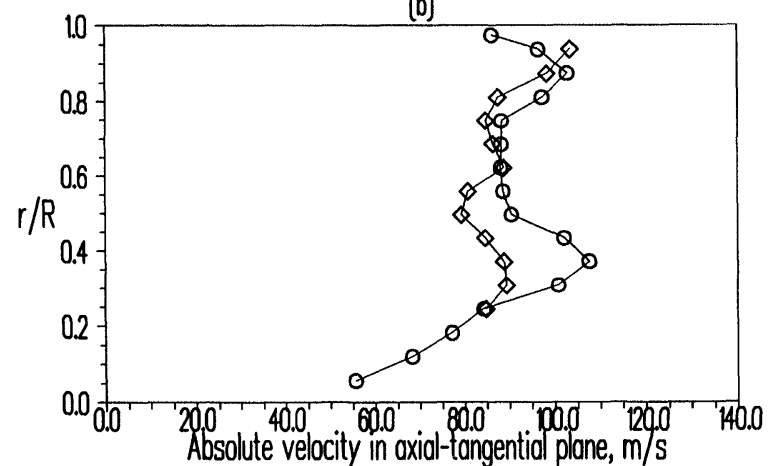

(c)

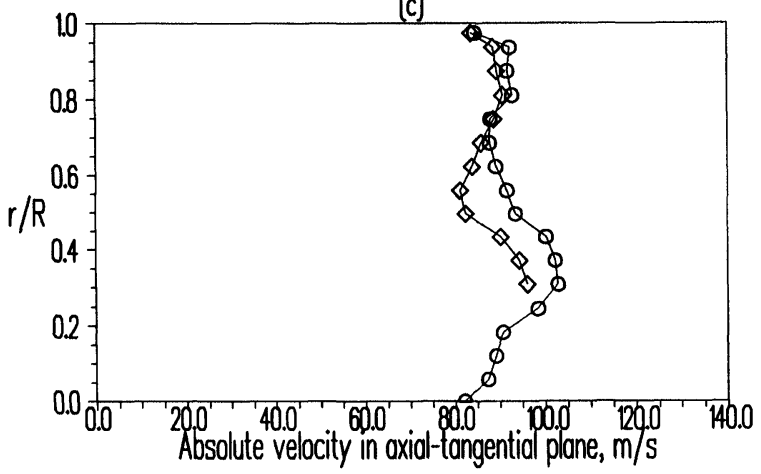

FIGURE 13 Exit absolute velocity of mixed-flow rotors B and $\mathrm{C}$ for the $70 \%$ equivalent design speed at three axial locations (a) $X=9.5 \mathrm{~mm}$; (b) $X=31.5 \mathrm{~mm}$; (c) $X=50.0 \mathrm{~mm}$.

the shroud to a minimum value close to $r / R=0.5$ for rotor $\mathrm{B}$ and $\mathrm{r} / \mathrm{R}=0.4$ for rotor $\mathrm{C}$ at $50 \%$, and $\mathrm{r} /$ $\mathrm{R}=0.45$ for rotor $\mathrm{B}$ and $\mathrm{r} / \mathrm{R}=0.375$ for rotor $\mathrm{C}$ at the $70 \%$ equivalent design speed. From then onwards a slight increase towards the hub can be seen due to the induced swirl from the hub rotation. The increase in the absolute flow angle becomes more pronounced at $\mathrm{X}=31.5 \mathrm{~mm}$ and 

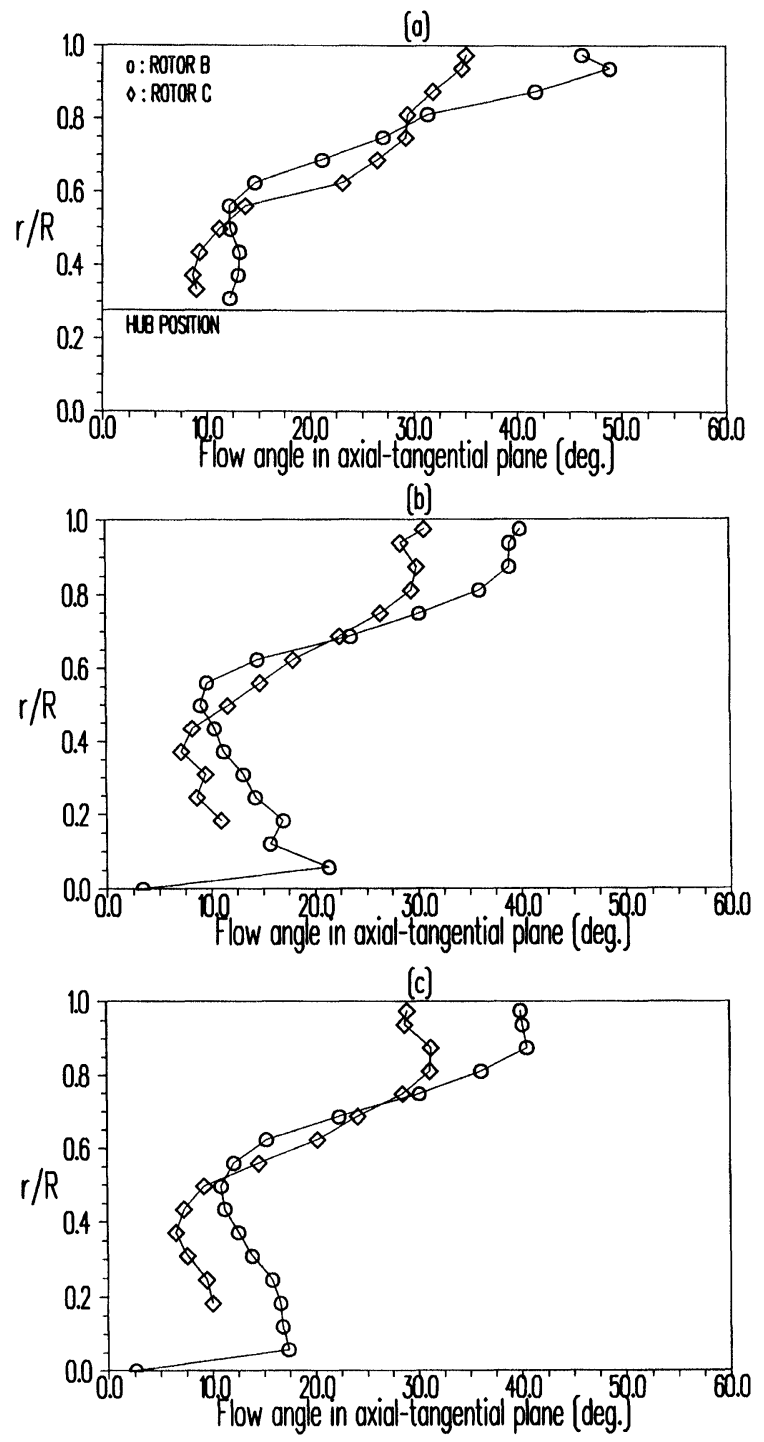

FIGURE 14 Exit absolute flow angle of mixed-flow rotors $\mathrm{B}$ and $\mathrm{C}$ for the $50 \%$ equivalent design speed at three axial locations (a) $X=9.5 \mathrm{~mm}$; (b) $X=31.5 \mathrm{~mm}$; (c) $X=50.0 \mathrm{~mm}$.

$50.0 \mathrm{~mm}$. It is clear that the flow angle for rotor B is considerably higher than that of rotor $\mathrm{C}$, especially close to the shroud. At the $X=9.5 \mathrm{~mm}$ exit plane, the maximum and minimum flow angles with rotor $\mathrm{C}$ at the lower speed are about $29 \%$ and $25 \%$ less than those for rotor $\mathrm{B}$; the corresponding differences at the higher speed are $40 \%$ and $47 \%$.

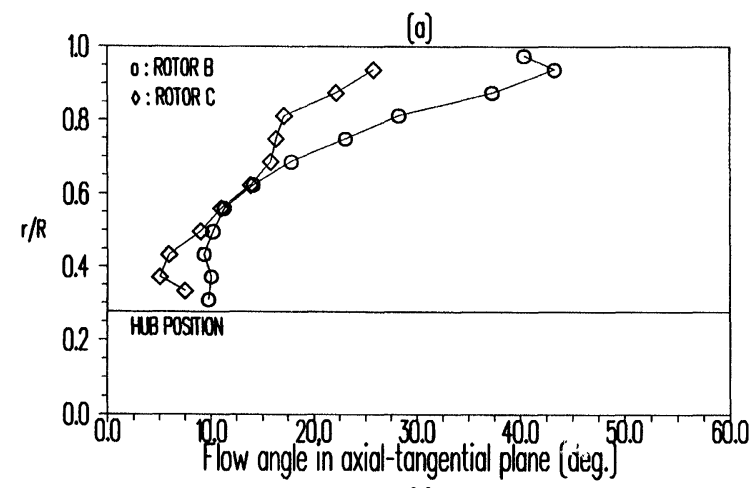

(b)

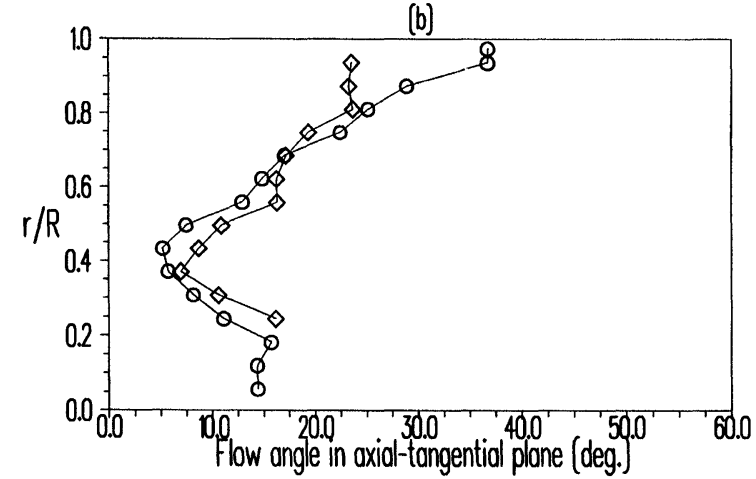

(c)

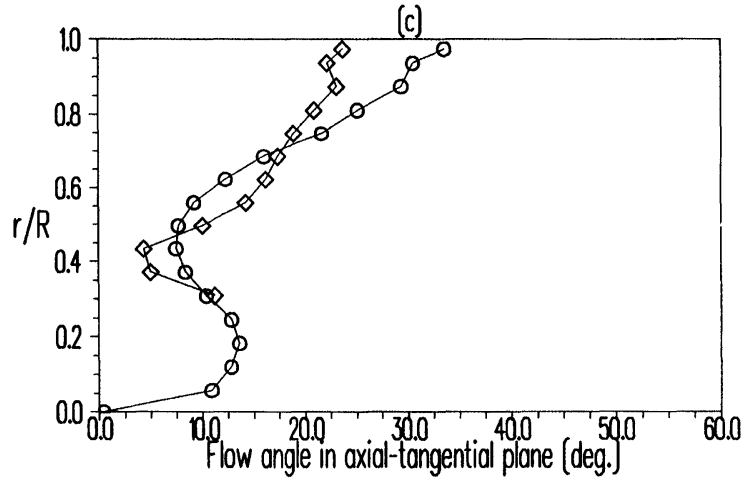

FIGURE 15 Exit absolute flow angle of mixed-flow rotors $\mathrm{B}$ and $\mathrm{C}$ for the $70 \%$ equivalent design speed at three axial locations (a) $X=9.5 \mathrm{~mm}$; (b) $X=31.5 \mathrm{~mm}$; (c) $X=50.0 \mathrm{~mm}$.

The results also show that there is an overall reduction in the flow angle as the speed increased from $50 \%$ to $70 \%$; this trend is more pronounced for rotor $\mathrm{C}$. The reduction in the maximum and minimum flow angles for rotor B as the speed increases from $50 \%$ to $70 \%$ design speeds at the exit plane is $11 \%$ and $21 \%$; the corresponding reduction 
for rotor $\mathrm{C}$ is $26 \%$ and $44 \%$. It is well known that the performance of a turbine depends on the exit flow angle. As the exit swirl velocities become smaller for a given rotational speed, the exit flow angle will decrease and the flow will become more axial. The reduced loss of exit kinetic energy can thus be expected to lead to an increase in efficiency, as long as there is not a significant increase in the internal loss generation which is controlled by the relative exit velocity magnitude (Whitfield [1990]).

Overall, the present experimental results show a correlation between turbine efficiency and exit flow angle. The turbine efficiency increased when the exit flow angle (or the swirl velocity) decreased from $50 \%$ to $70 \%$ equivalent design speed. Besides, the exit flow angle of rotor $\mathrm{C}$ with the fewer number of blades, longer overall rotor blade length and constant inlet blade angle across the span was smaller than rotor B, which agrees with its higher efficiency.

\section{CONCLUSIONS}

The effect of the volute geometry on the performance of mixed-flow turbines has been examined under steady-state conditions for two volutes and two different rotors. The exit flow characteristics of the two rotors were quantified by laser Doppler velocimetry for $50 \%$ and $70 \%$ equivalent design speed. The main findings can be summarised as follows:

1. The overall total-to-static efficiencies of both rotors increased with speed up to $70 \%$ equivalent design speed after which they remained almost constant except close to the surge conditions. The overall efficiency of rotor $\mathrm{C}$ having constant blade angle was higher than that of rotor B (constant incidence) by up to 2.5 percentage points.

2. The effect of the volute configuration on turbine performance revealed that the new volute having a larger swallowing capacity gave rise to a higher efficiency at lower speeds. With the new volute the isentropic efficiency achieved a maximum at $70 \%$ design speed, compared with the $90 \%$ design speed for the old volute. The results also showed that the variation of efficiency with respect to pressure ratio for a fixed rotational speed was much flatter with the new volute. These results indicate that careful investigation of the volute geometry should be carried out, particularly in a nozzleless device.

3. The axial velocity results for the $50 \%$ and $70 \%$ equivalent design speeds showed different and non-uniform exit flows, with rotor $\mathrm{B}$ being slightly more uniform, indicating different flow structures within the blade passage. Further downstream, the flow distribution becomes more uniform with the differences in the exit flow between the two rotors significantly reduced.

4. The exit swirl velocities with both rotors exhibited two distinct flow regions, one close to the shroud where velocities reduce from a maximum value in the vicinity of the shroud to a minimum in the annular core region in a manner similar to that of solid body rotation, and a second region close to the hub which is almost uniform with a gradual increase towards the hub. The results also showed that rotor B generated higher swirl velocities than rotor $\mathrm{C}$ at all locations and for both rotational speeds.

5. Large variations in the exit flow angles were seen at all axial planes and both speeds, following closely the trend of the tangential velocity variation with maximum angle in the vicinity of the shroud. The exit flow angles were reduced as the rotor speed was increased and the flow angles with rotor $\mathrm{C}$ were considerably lower than those of rotor B.

6. A reduction in the exit flow angle was accompanied with an increase in the overall turbine performance suggesting a close correlation between these two characteristics.

\section{NOMENCLATURE}

$C_{i s} \quad$ isentropic expansion velocity

$C_{p} \quad$ specific heat capacity at constant pressure

$d \quad$ Saunter mean diameter; rotor mean diameter 
$L \quad$ length of blade span at rotor exit; rotor length

M.P. mass flow parameter

$\dot{m}$ mass flow rate

$N \quad$ rotational speed

$P \quad$ pressure

P.R. pressure ratio

$\dot{Q} \quad$ power

$R \quad$ exit pipe inner radius

$r \quad$ radial distance

$T$ temperature

$U \quad$ Turbine rotor speed; air velocity; axial mean velocity

$W \quad$ tangential velocity

$\dot{W}$ power

$x \quad$ axial distance from the trailing edge

$\alpha \quad$ absolute flow angle

$\eta \quad$ efficiency

$\mu \quad$ viscosity

$\rho \quad$ density

$\tau \quad$ time response

\section{Subscripts}

0 total or stagnation value

1 turbine inlet

2 rotor inlet

3 turbine exit

act actual

c compressor

$e \quad$ turbine exit

$f \quad$ flow

is isentropic

$p \quad$ particle

$T$ turbine

$t \quad$ rotor tip

$t-s \quad$ total-to-static

\section{Acknowledgment}

The authors would like to thank the Engineering and Physical Sciences Research Council for providing Grant GR/J14226 and Holset Engineering Company Limited for technical support and useful discussions.

\section{References}

Abidat, M. (1991) Design and testing of a highly loaded mixed flow turbine, Ph.D. Thesis, Imperial College of Science, Technology and Medicine, University of London.

Abidat, M., Chen, H., Baines, N.C. and Firth, M.R. (1992) Design of highly loaded mixed flow turbine, Proc. Inst. Mech. Engrs., J. Power and Energy, 206, 95-107.

Arcoumanis, C., Hakeem, I., Khezzar, L., Martinez-Botas, R.F. and Baines, N.C. (1995) Performance of a mixed flow turbocharger turbine under pulsating flow conditions, ASME paper 95-GT-210.

Arcoumanis, C., French, B. and Nouri, J.M. (1996) Steady intake flow characteristics through a diesel four-valve cylinder head, 8th Int. Symp. appl. Laser Tech. to Fluid Mechanics, Lisbon, July 8-11,1, 16.3.1-16.3.14.

Baines, N.C. and Yeo, J.H. (1991) Flow in a radial turbine under equal and partial admission conditions, Euro. Turbomachinery Conf., I. Mech. E., C423/002.

Benisek, E. (1994) Comparisons of laser measurements and pneumatic measurements in a turbocharger turbine, Euro. Turbomachinery Conf., I. Mech. E., C484/018.

BS1042 (1981) Methods of measurement of fluid flow in closed conditions, Part 1: Pressure differential device, Section 1.1: Orifice plates, nozzles and Venturi tubes inserted in circular cross-section conduits running full, British Standards Institution.

Chen, H., Abidat, M., Baines, N.C. and Firth, M.R. (1992) The effect of blade loading in radial and mixed flow turbines, ASME, Int. Gas Turbine and Aeroengine Congress and Exhibition, Cologne, Germany, June 1-4.

Chou, C.C. and Gibbs, C.A. (1989) The design and testing of a mixed flow turbine for turbochargers, SAE paper 890644

Dale, A. and Watson, N. (1986) Vaneless radial turbocharger turbine performance, I. Mech. E. paper C110/86.

Elder, R.L., Forster, C.P. and Gill, M.E. (1986) Application of Doppler and transit anemometry in small turbomachines, Paper 10, AGARD-CP-399.

Hakeem, I. and Khezzar, L. (1994) The turbocharger aerodynamic test facility - description and operation, Imperial College of Science, Technology and Medicine, University of London, Internal report TF/94/37.

Hakeem, I. (1995) Steady and unsteady performance of mixed flow turbines for automotive turbochargers, Ph.D. Thesis, Imperial College of Science, Technology and Medicine, University of London.

Ikeya, N., Yamaguchi, H., Mitsubori, K. and Kondoh, N. (1992) Development of advanced model of turbocharger for automotive engines, SAE paper 920047.

Khezzar, L., Vafidis, C. and Whitelaw, J.H. (1987) Laser velocimetry for the measurement of air velocity in a centrifugal compressor, Imperial College of Science, Technology and Medicine, University of London, Internal report FS $/ 87 / 36$.

Kitson, S.T., Maguire, J.M., Langdon, P.J., Varo, R.G. and Shaw, G.D., (1990) The computational experiment applied to aerodynamic design and analysis of turbomachinery, SAE paper 900360

Martinez-Botas, R.F., Pullen, K.R. and Shi, F. (1996) Numerical calculations of a turbine volute using a 3-D Navier-Stokes solver, ASME paper 96-GT-66.

Minegishi, H., Matsushita, H., Sakakida, M. and Koike, T. (1995) Development of a small mixed-flow turbine for automotive turbochargers, ASME paper 95-GT-53. 
Murugan, D.M., Tabakoff, W. and Hamed, A. (1994) Flow field investigation in the exit region of a radial inflow turbine using LDV, ASME, Int. Gas Turbine and Aeroengine Congress and Exhibition, Hague, Netherlands, June 13-16.

Naguib, M. (1986) Experience with the modern RR151 turbocharger for high speed diesel engines, Proc. Int. Conf. on Turbochargers and Turbocharging, I. Mech. E., C99/86.

Rodgers, C. (1990) Review of mixed flow and radial turbine options, AIAA paper 902414.

Schodl, R. (1986) Laser two focus velocimetry, AGARD-CP 399, Advance Inst. for Aero engine components.

Tsujita, M., Niino, S., Ishizuka, T., Kakinai, A. and Sato, A. (1993) Advanced fuel economy in Hino new P11c turbo- charged and charged-cooled heavy duty diesel engine, SAE paper 930272.

Watson, N. and Janota, M.S. (1982) Turbocharging the internal combustion engine, The Macmillan Press Limited.

Whitfield, A. (1990) The preliminary design of radial inflow turbines, Journal of Turbomachinery, 112, 50-57.

Zaidi, S.H. and Elder, R.L. (1993) Investigation of flow in a radial turbine using laser anemometry, ASME, Int. Gas Turbine and Aeroengine Congress and Exhibition, Cincinnati, Ohio, May 24-27, ASME paper 93-GT-55. 


\section{ait \\ ENERGY MATERIALS}

M A N E Y publishing

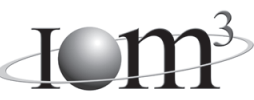

\section{Materials Science \& Engineering for Energy Systems}

Maney Publishing on behalf of the Institute of Materials, Minerals and Mining

The Institute of Materials, Minerals \& Mining

Economic and environmental factors are creating ever greater pressures for the efficient generation, transmission and use of energy. Materials developments are crucial to progress in all these areas: to innovation in design; to extending lifetime and maintenance intervals; and to successful operation in more demanding environments. Drawing together the broad community with interests in these areas, Energy Materials addresses materials needs in future energy generation, transmission, utilisation, conservation and storage. The journal covers thermal generation and gas turbines; renewable power (wind, wave, tidal, hydro, solar and geothermal); fuel cells (low and high temperature); materials issues relevant to biomass and biotechnology; nuclear power generation (fission and fusion); hydrogen generation and storage in the context of the 'hydrogen economy'; and the transmission and storage of the energy produced.

As well as publishing high-quality peer-reviewed research, Energy Materials promotes discussion of issues common to all sectors, through commissioned reviews and commentaries. The journal includes coverage of energy economics and policy, and broader social issues, since the political and legislative context influence research and investment decisions.

\section{CALL FOR PAPERS}

Contributions to the journal should be submitted online at http://ema.edmgr.com

To view the Notes for Contributors please visit: www.maney.co.uk/journals/notes/ema

Upon publication in 2006, this journal will be available via the Ingenta Connect journals service. To view free sample content online visit: www.ingentaconnect.com/content/maney

For further information please contact:

Maney Publishing UK

Tel: +44 (0)113 2497481 Fax: +44 (0)1132486983 Email: subscriptions@maney.co.uk

or

Maney Publishing North America

Tel (toll free): 8662975154 Fax: 6173546875 Email: maney@maneyusa.com

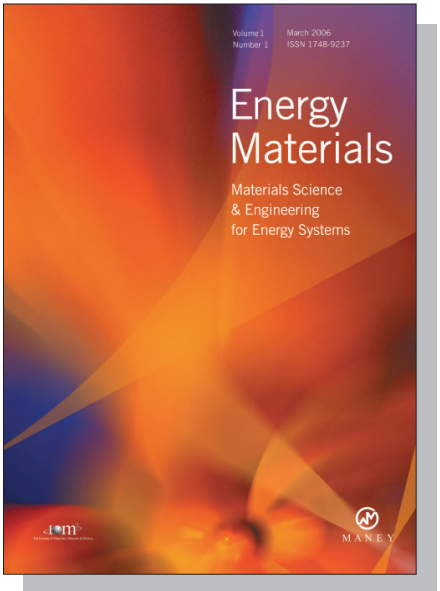

EDITORS

Dr Fujio Abe

NIMS, Japan

Dr John Hald, IPL-MPT, Technical University of Denmark, Denmark

Dr R Viswanathan, EPRI, USA

\section{SUBSCRIPTION INFORMATION}

Volume 1 (2006), 4 issues per year

Print ISSN: 1748-9237 Online ISSN: 1748-9245

Individual rate: $£ 76.00 / U S \$ 141.00$

Institutional rate: $£ 235.00 /$ US $\$ 435.00$

Online-only institutional rate: $£ 199.00 / U S \$ 367.00$

For special $\mathrm{IOM}^{3}$ member rates please email

subscriptions@maney.co.uk

\section{For further information or to subscribe online please visit www.maney.co.uk}



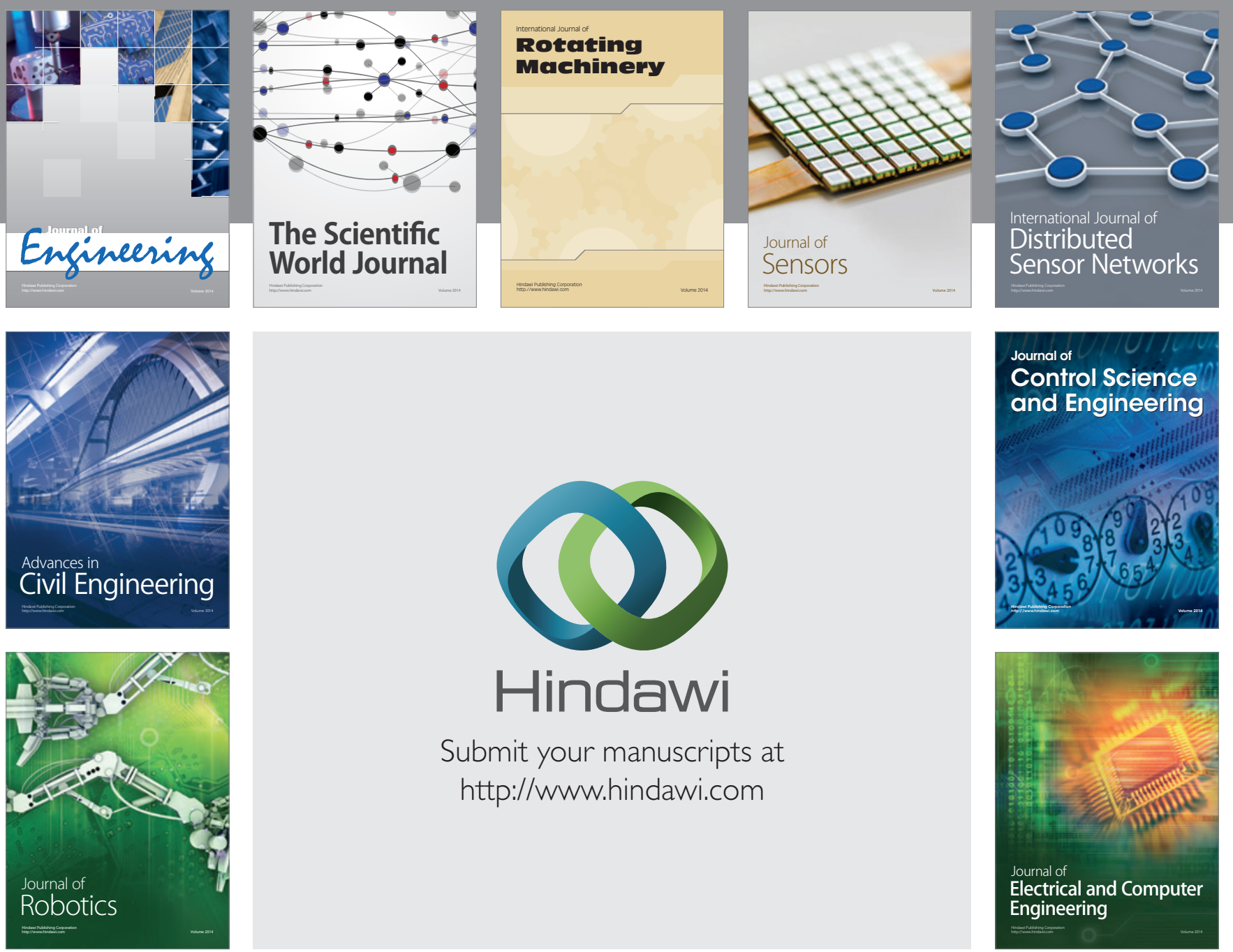

Submit your manuscripts at

http://www.hindawi.com
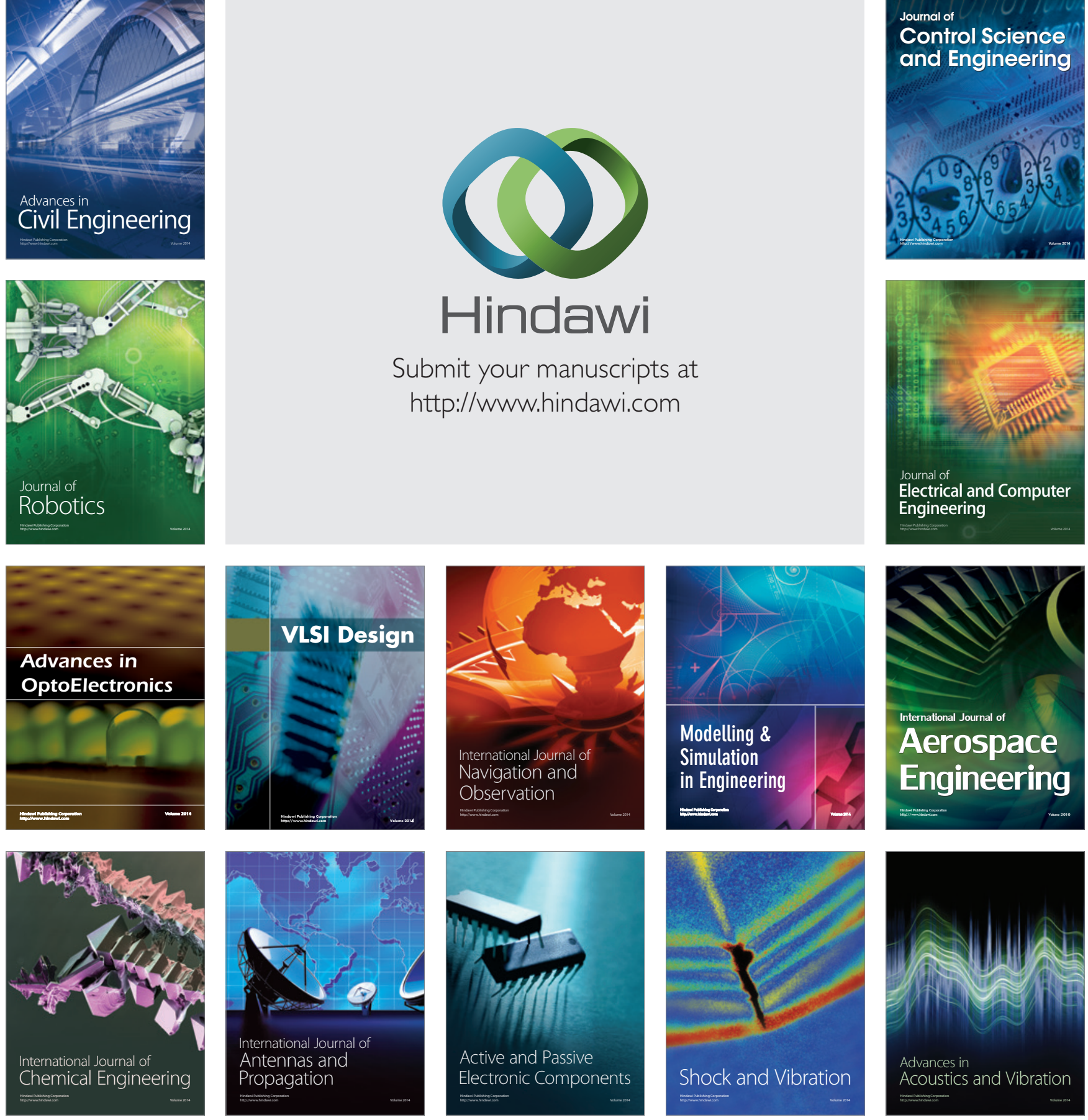